Research Article

\title{
The Complexity Uncertain Analysis about Three Differences Old and New Product Pricing Oligarch Retailers Closed-Loop Supply Chain
}

\author{
Junhai Ma and Bin Chen \\ College of Management and Economics, Tianjin University, Tianjin 300072, China \\ Correspondence should be addressed to Junhai Ma; lzqsly@126.com
}

Received 14 January 2014; Revised 27 April 2014; Accepted 12 May 2014; Published 10 June 2014

Academic Editor: Haydar Akca

Copyright (C) 2014 J. Ma and B. Chen. This is an open access article distributed under the Creative Commons Attribution License, which permits unrestricted use, distribution, and reproduction in any medium, provided the original work is properly cited.

This paper studied some realistic recycle fields at present in China, such as some daily machinery and equipment, electronic products, and plastic products. Under such circumstance, three oligarch retailers are a common situation. In this paper, we model and analyze the game of three oligarch retailers in a closed-loop supply chain. The stability of the Nash equilibrium, the bifurcation and chaos phenomenon of the recycling price and new product quantity when retailers change its adjustment speed, the profit trends of the three retailers, and the power spectrum are studied. At last, we used the parameter adjustment and the variable state feedback control strategy for chaos control, and the chaos of the system is delayed effectively. For closed-loop supply chain research, the conclusions of the numerical simulation in this paper not only have realistic guiding significance, but also have theoretical reference value.

\section{Introduction}

As an effective method for studying multistage decision problems in supply chain, game and complexity theory has been an enduring one. Zhang and $\mathrm{Da}$ [1] built a duopoly game model with different cost structures and studied the Nash equilibrium and the chaos of the model. Matsumoto and Nonaka [2] analyzed the complexity of a Cournot model with linear cost function. Lu et al. [3] studied a duopoly game model and its chaos control. Elabbasy et al. [4] discussed three different decision makers, bounded rationality, adaptive, and naïve, and studied the three-oligarch game under this situation. Gong and Li [5] analyzed a three-oligarch game based on two different structures which used differentiation competition and discrimination pricing strategy. $\mathrm{Hu}$ and Chen [6] considered a duopoly game with learning ability and its chaos control. $\mathrm{Ma}$ and $\mathrm{Pu}[7,8]$ considered the nonlinear three-oligarch market and its complexity and discussed a Cournot-Bertrand model and its complexity characteristics. Zhang and Ma [9] studied the chaos and chaos control of a four-oligarch game. Ma and Sun [10] analyzed the complexity characteristics of a three-oligarch price game with heterogeneous decision rules. Wang and $\mathrm{Ma}$ [11] studied a Cournot-Bertrand game model and its complexity with limited information.

Meanwhile, the game and complexity theory has been applied to different realistic fields. Ma and Bangura [12] applied complexity theory to financial and economic system. Junhai and Junling [13] used complexity theory to study insurance market and achieved some results. Ma and Tu [14] applied complexity theory to power market and discussed the chaos in duopoly game with bounded rationality, when delay was considered. Sun and Ma [15] researched Chinese cold rolled steel market and analyzed the complexity of a three-oligarch game based on Bertrand model. Ding et al. [16] studied an advertising game model and its chaos control using game and complexity theory. Yi [17] discussed the game model of a closed-loop supply chain with one manufacturer and two retailers. Guo et al. [18] considered a closed-loop supply chain with duopoly manufacturers and studied the chaos when the manufacturers recycled the waste products. $\mathrm{Ma}$ and Zhao [19] discussed the influence of the government replacement subside on four different types of closed-loop supply chain in three aspects. 
Based on others' former research, for the realistic recycle fields at present in China, such as some daily machinery and equipment, electronic products, and plastic products, we build a closed-loop supply chain model with three oligarch retailers in this paper. According to this model, the retailers recycle the waste products, return them to the manufacturer for repair, and then sell the second-hand products after fix and new products together. After being repaired, the second-hand products are the same as the new products in performance and appearance, but they have different customer approval degree, so their prices are different.

To be more realistic, this paper builds a three oligarch retailers competing model based on price difference between new and second-hand products. The stability of the Nash equilibrium is discussed in this paper; through bifurcation diagram, the maximum Lyapunov index diagram, and attractor, the stability and chaos of the system are studied; the trends of the three oligarch retailers' profit and the system average profit are researched. At last, we successfully controlled the chaos of the system.

\section{The Model}

2.1. Assumptions and Symbols. At present, the research on closed-loop supply chain at home and abroad is mainly for game equilibrium with different market structures, in which role of the supply chain is to recycle the waste products and so on. Very few papers considered the new and secondhand product market together and rarely applied complexity theory to the combination market. This paper focuses on the new and second-hand combination market and considers the game and complexity of the three oligarch retailers in the closed-loop supply chain. In this model, the retailers recycle the waste products, return them to the manufacturer for repair, and pay some cost to the manufacturer for repair. After repair, the retailers sell the second-hand products and the new products together. The second-hand products have no difference in performance and appearance from the new products, but the difference in customer approval degree between them results in different prices. In this closedloop supply chain, the manufacturer provides new products and fixes waste products; three retailers are three oligarchs; they recycle waste products and sell new and second-hand products.

Assumptions are as follows:

(1) three retailers $R 1, R 2$, and $R 3$ are all independent decentralized decision makers, and they are all bounded rationally; at discrete time periods $t=$ $1,2, \ldots$, each retailer makes its decision to maximize its own profit;

(2) the recycle quantity of each retailer is related to its own and competitors' recycle prices;

(3) the manufacturer can repair all the waste products, with no waste in repair process;

(4) for the difference in customer approval degree between new and second-hand products, their price is different;
(5) demand is bigger than supply, so the new and secondhand products can both sell out, but price decreases when supply increases.

Symbols are as follows:

(1) manufacturer $M$ : new product wholesale price $w$; waste product repair cost $c$;

(2) retailer $R_{i}$ : waste product recycle price $p_{i}$; waste product recycle quantity $r_{i}$; second-hand product fixed cost of sale $c_{r_{i}}$; second-hand product market price $p_{r}$; new product supply quantity $q_{i}$; new product fixed cost of sale $c_{n_{i}}$; new product market price $p_{n}$.

2.2. Model Dynamical System. For the three oligarch retailers, the functions of each one's waste products recycle quantity are as follows:

$$
\begin{aligned}
& r_{1}=g_{1}+h_{1} p_{1}-j_{1} p_{2}-k_{1} p_{3}, \\
& r_{2}=g_{2}+h_{2} p_{2}-j_{2} p_{1}-k_{2} p_{3}, \\
& r_{3}=g_{3}+h_{3} p_{3}-j_{3} p_{1}-k_{3} p_{2} .
\end{aligned}
$$

In the previous equation, $g_{i} \geq 0(i=1,2,3)$ is the recycle quantity that the customers returned to retailer $i$ for free, based on their environmental protection consciousness; $h_{i} \geq$ $0(i=1,2,3)$ is the customers' recycle price sensitive coefficient; $j_{i}, k_{i} \geq 0(i=1,2,3)$ is the retailers' competition coefficient, and $h_{i}>j_{i}, h_{i}>k_{i}(i=1,2,3)$.

The functions of the new and second-hand products' price are as follows:

$$
\begin{aligned}
& p_{n}=a_{1}-b_{1}\left(q_{1}+q_{2}+q_{3}\right)-d_{1}\left(r_{1}+r_{2}+r_{3}\right), \\
& p_{r}=a_{2}-b_{2}\left(r_{1}+r_{2}+r_{3}\right)-d_{2}\left(q_{1}+q_{2}+q_{3}\right) .
\end{aligned}
$$

In the previous equation, $a_{i}>0$ is the maximum demand of the market; $b_{i}>0, d_{i}>0$ is the replacement ratio between new and second-hand products. Then we get the profit of retailer $i$ at period

$$
\begin{aligned}
\pi_{i}(t)= & \left(p_{r}(t)-p_{i}(t)-c-c_{r_{i}}\right) * r_{i}(t) \\
& +\left(p_{n}(t)-w-c_{n_{i}}\right) * q_{i}(t) .
\end{aligned}
$$

Each retailer has two decision variables: recycle price $p_{i}$ and new product supply quantity $q_{i}$; then the marginal profit functions of the three oligarch retailers at period $t$ are according to the principle that maximizes its benefit, and in that time the marginal benefit is equal to 0 :

$$
\frac{\partial \pi_{i}(t)}{\partial p_{i}(t)}, \frac{\partial \pi_{i}(t)}{\partial q_{i}(t)}=0 \quad(i=1,2,3) .
$$

In real economic circumstance, the three oligarch retailers are all information limited; under the bounded rational decision rule, each retailer at period $t+1$ takes the adjustment strategy:

$$
\begin{gathered}
p_{i}(t+1)=p_{i}(t)+v_{i} p_{i}(t) \frac{\partial \pi_{i}(t)}{\partial p_{i}(t)}, \\
q_{i}(t+1)=q_{i}(t)+\alpha_{i} q_{i}(t) \frac{\partial \pi_{i}(t)}{\partial q_{i}(t)} \quad(i=1,2,3) .
\end{gathered}
$$


In the previous equation, $v_{i}, \alpha_{i} \geq 0(i=1,2,3)$ are the adjustment speed of retailer $i$ for its recycle price $p_{i}$ and new product supply quantity $q_{i}$.

Integrate formulas (1)-(5); then we get the discrete dynamic system of the three oligarch retailers in this closedloop supply chain:

$$
\begin{aligned}
& p_{1}(t+1)=p_{1}(t)+v_{1} p_{1}(t) \\
& \times\left(A_{1} p_{1}(t)+A_{2} p_{2}(t)+A_{3} p_{3}(t)\right. \\
& +A_{4} q_{1}(t)-d_{2} h_{1} q_{2}(t) \\
& \left.-d_{2} h_{1} q_{3}(t)+A_{5}\right), \\
& p_{2}(t+1)=p_{2}(t)+v_{2} p_{2}(t) \\
& \times\left(B_{1} p_{1}(t)+B_{2} p_{2}(t)\right. \\
& +B_{3} p_{3}(t)-d_{2} h_{2} q_{1}(t) \\
& \left.+B_{4} q_{2}(t)-d_{2} h_{2} q_{3}(t)+B_{5}\right), \\
& p_{3}(t+1)=p_{3}(t)+v_{3} p_{3}(t) \\
& \times\left(C_{1} p_{1}(t)+C_{2} p_{2}(t)\right. \\
& +C_{3} p_{3}(t)-d_{2} h_{3} q_{1}(t) \\
& \left.-d_{2} h_{3} q_{2}(t)+C_{4} q_{3}(t)+C_{5}\right), \\
& q_{1}(t+1)=q_{1}(t)+\alpha_{1} q_{1}(t) \\
& \times\left(D_{1} p_{1}(t)+D_{2} p_{2}(t)\right. \\
& +D_{3} p_{3}(t)-2 b_{1} q_{1}(t) \\
& \left.-b_{1} q_{2}(t)-b_{1} q_{3}(t)+D_{4}\right), \\
& q_{2}(t+1)=q_{2}(t)+\alpha_{2} q_{2}(t) \\
& \times\left(E_{1} p_{1}(t)+E_{2} p_{2}(t)\right. \\
& +E_{3} p_{3}(t)-b_{1} q_{1}(t) \\
& \left.-2 b_{1} q_{2}(t)-b_{1} q_{3}(t)+E_{4}\right), \\
& q_{3}(t+1)=q_{3}(t)+\alpha_{3} q_{3}(t) \\
& \times\left(F_{1} p_{1}(t)+F_{2} p_{2}(t)\right. \\
& +F_{3} p_{3}(t)-b_{1} q_{1}(t) \\
& \left.-b_{1} q_{2}(t)-2 b_{1} q_{3}(t)+F_{4}\right) .
\end{aligned}
$$

\section{Numerical Simulation Analyses}

3.1. The Equilibrium of System and Its Stability. In order to study the behavior of different retailers, we need to solve the equilibrium of discrete dynamic system (6) and then discuss its stability. Here we will study the connection between the equilibrium, its stability, and the decision behavior of each retailer. To be clear, first we assign a value for the market parameters, which are beyond the range of the retailers' decision.

At present in China, the recycling industry is still in its infancy; besides the customers' environmental protection consciousness is weak, so the customers' recycle price sensitivity would be strong. From the customer psychology, even though the new and second-hand products have no difference in their performance and appearance, the new product would have a higher price. Based on the actual investigation of Chinese retail market, we find that the situation is in this case, especially in the sales process of some high price products. This situation is more obvious; therefore, according to the actual statistical data, the values of the market parameters are assigned as follows:

$$
\begin{aligned}
& a_{1}=28, \quad a_{2}=22, \quad b_{1}=0.8, \quad b_{2}=0.7, \\
& d_{1}=0.3, \quad d_{2}=0.5 ; \quad c=2, \quad w=10, \\
& c_{r 1}=0.2, \quad c_{r 2}=0.18, \quad c_{r 3}=0.21, \quad c_{n 1}=0.3, \\
& c_{n 2}=0.32, \quad c_{n 3}=0.27 ; \quad g_{1}=0.3, \\
& g_{2}=0.25, \quad g_{3}=0.27, \quad k_{1}=0.25, \quad k_{2}=0.24 \text {, } \\
& k_{3}=0.26 ; \quad h_{1}=1.2, \quad h_{2}=0.95, \quad h_{3}=1.1 \text {, } \\
& j_{1}=0.2, \quad j_{2}=0.21, \quad j_{3}=0.19 .
\end{aligned}
$$

Discrete dynamic system (6) is a six-dimension space; the equilibriums of the system are the fixed points of the space, and there are 64 of them. As in realistic supply chain, any oligopoly will not make the price at 0 or have no production in the actual production process. Therefore, the quantity and price at equilibrium point need to be positive. From the calculated results, we find that 63 of the equilibriums are not totally positive, so they are meaningless in reality. Due to limited space, the 63 solutions are not listed. Here we will only solve the positive equilibrium $E$, and it is the only Nash equilibrium of the system; its value is as follows:

$$
\begin{aligned}
E= & {\left[p_{1}^{*}, p_{2}^{*}, p_{3}^{*}, q_{1}^{*}, q_{2}^{*}, q_{3}^{*}\right] } \\
= & {[4.4641,4.9662,4.7060,} \\
& 4.2869,4.4451,4.3806] .
\end{aligned}
$$

We can see that retailers' adjustment speed $v_{i}, \alpha_{i}$ has no influence on the value of the Nash equilibrium $E$. When the market parameters remain the same, the value of the equilibrium $E$ would not change with the adjustment speed.

Next we will discuss the stability of the equilibrium; the Jacobian matrix of discrete dynamic system (6) is as follows: 


$$
J\left(p_{1}, p_{2}, p_{3}, q_{1}, q_{2}, q_{3}\right)=\left[\begin{array}{cccccc}
1+v_{1} A & v_{1} A_{2} p_{1} & v_{1} A_{3} p_{1} & v_{1} A_{4} p_{1} & -d_{2} h_{1} v_{1} p_{1} & -d_{2} h_{1} v_{1} p_{1} \\
v_{2} B_{1} p_{2} & 1+v_{2} B & v_{2} B_{3} p_{2} & -d_{2} h_{2} v_{2} p_{2} & v_{2} B_{4} p_{2} & -d_{2} h_{2} v_{2} p_{2} \\
v_{3} C_{1} p_{3} & v_{3} C_{2} p_{3} & 1+v_{3} C & -d_{2} h_{3} v_{3} p_{3} & -d_{2} h_{3} v_{3} p_{3} & v_{3} C_{4} p_{3} \\
\alpha_{1} D_{1} q_{1} & \alpha_{1} D_{2} q_{1} & \alpha_{1} D_{3} q_{1} & 1+\alpha_{1} D & -b_{1} \alpha_{1} q_{1} & -b_{1} \alpha_{1} q_{1} \\
\alpha_{2} E_{1} q_{2} & \alpha_{2} E_{2} q_{2} & \alpha_{2} E_{3} q_{2} & -b_{1} \alpha_{2} q_{2} & 1+\alpha_{2} E & -b_{1} \alpha_{2} q_{2} \\
\alpha_{3} F_{1} q_{3} & \alpha_{3} F_{2} q_{3} & \alpha_{3} F_{3} q_{3} & -b_{1} \alpha_{3} q_{3} & -b_{1} \alpha_{3} q_{3} & 1+\alpha_{3} F
\end{array}\right] .
$$

In the previous matrix, $A=\partial \pi_{1} / \partial p_{1}+A_{1} p_{1}, B=\partial \pi_{2} / \partial p_{2}+$ $B_{2} p_{2}, C=\partial \pi_{3} / \partial p_{3}+C_{3} p_{3}, D=\partial \pi_{1} / \partial q_{1}-2 b_{1} q_{1}$, $E=\partial \pi_{2} / \partial q_{2}-2 b_{1} q_{2}$, and $F=\partial \pi_{3} / \partial q_{3}-2 b_{1} q_{3}$.
For Nash equilibrium $E$, its Jacobian matrix is as follows:

$$
J(E)=\left[\begin{array}{cccccc}
1-16.7134 v_{1} & -0.4446 v_{1} & -0.5464 v_{1} & -2.4106 v_{1} & -1.3392 v_{1} & -1.3392 v_{1} \\
-1.2414 v_{2} & 1-12.6722 v_{2} & -0.4138 v_{2} & -1.1795 v_{2} & -1.9095 v_{2} & -1.1795 v_{2} \\
-1.6230 v_{3} & -0.0296 v_{3} & 1-14.774 v_{3} & -1.2941 v_{3} & -1.2941 v_{3} & -2.1553 v_{3} \\
-2.3149 \alpha_{1} & -0.4158 \alpha_{1} & -0.5166 \alpha_{1} & 1-6.8591 \alpha_{1} & -3.4295 \alpha_{1} & -3.4295 \alpha_{1} \\
-0.8335 \alpha_{2} & -1.7091 \alpha_{2} & -0.5467 \alpha_{2} & -3.5561 \alpha_{2} & 1-7.1121 \alpha_{2} & -3.5561 \alpha_{2} \\
-0.8433 \alpha_{3} & -0.3592 \alpha_{3} & -2.0063 \alpha_{3} & -3.5045 \alpha_{3} & -3.5045 \alpha_{3} & 1-7.009 \alpha_{3}
\end{array}\right]
$$

From the Jacobian matrix of equilibrium $E$, we know that although the retailers' adjustment speed $v_{i}, \alpha_{i}$ has no influence on the value of equilibrium $E, v_{i}, \alpha_{i}$ affect the stability of $E$. So the Nash equilibrium is local stable, but its stability needs to meet certain conditions. The size of its stability range is decided by the retailers' adjustment speed to their recycle price and new product supply quantity.

3.2. Bifurcation and Chaos Numerical Simulation. From the Jacobian matrix of equilibrium $E$, we know that the retailers' adjustment speed $v_{i}, \alpha_{i}$ has influence on the stability of the Nash equilibrium $E$. As the three retailers are three oligarchs, theoretically they have a similar impact on the system, so we use $v_{1}, \alpha_{1}$, for example, to study the influence of $v_{i}, \alpha_{i}$ on the system variables.

Take $v_{2}=0.05, v_{3}=0.1, \alpha_{1}=0.1, \alpha_{2}=0.15$, and $\alpha_{3}=$ 0.05 ; we get the track figures of each retailer's recycle price $p_{i}$ and new product supply quantity $q_{i}$, when $v_{1}$ gradually increases from zero (Figure 1 is the track figure of $p_{i}$ with $v_{1}$, and Figure 2 is the track figure of $q_{i}$ with $v_{1}$ ). Take $v_{1}=0.05$, $v_{2}=0.12, v_{3}=0.1, \alpha_{2}=0.1$, and $\alpha_{3}=0.15$; we get the track figures of each retailer's recycle price $p_{i}$ and new product supply quantity $q_{i}$, when $\alpha_{1}$ gradually increases from zero (Figure 3 is the track figure of $p_{i}$ with $\alpha_{1}$, and Figure 4 is the track figure of $q_{i}$ with $\alpha_{1}$ ).

From Figures 1 to 4 we see that when the adjustment speed $v_{1}, \alpha_{1}$ of retailer 1 gradually increases, at first each retailer's recycle price $p_{i}$ and new product supply quantity $q_{i}$ all stay stable; then the first bifurcation came up, the second bifurcation came up, and at last it came to chaos. It means that if retailer 1 adjusts its recycle price $p_{1}$ or its new product

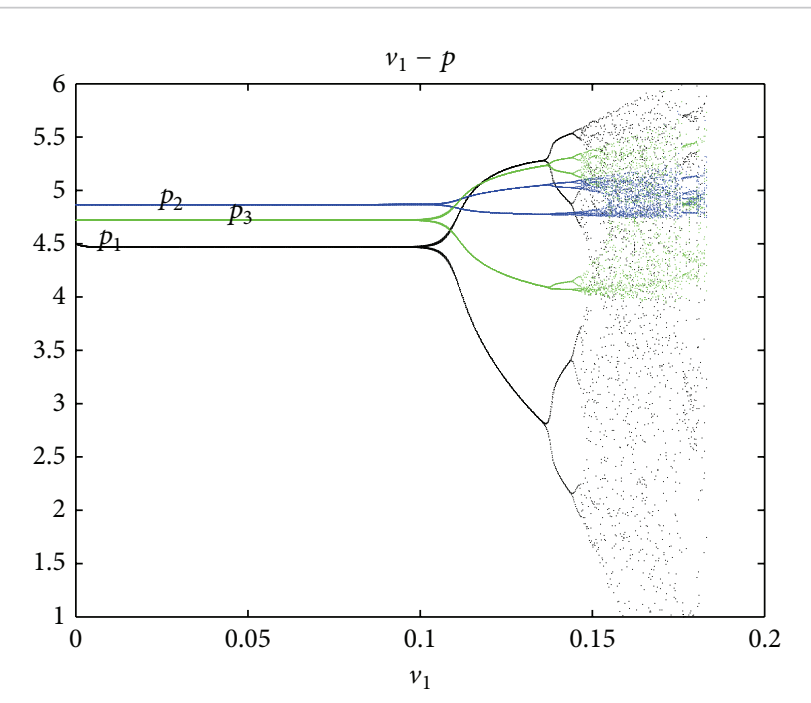

FIgURE 1: Price bifurcation with the change of $v_{1}$.

supply quantity $q_{1}$ too fast, all the retailers' behavior will become unpredictable and complicated. Similarly, if retailer 2 and retailer 3 adjust their recycle price $p_{i}$ or their new product supply quantity $q_{i}$ too fast, it will also cause disorder of the market. What is more, from Figures 1-2, we can know that, with the increase of $v_{1}$, the price of retailer 1 enters into the bifurcation condition first and then that of retailers 3 and 2. In quantity aspect, retailer 1 first entered the bifurcation condition and then retailers 2 and 3 . This shows that, in this state, the different research objectives have different paths entering into chaos. 


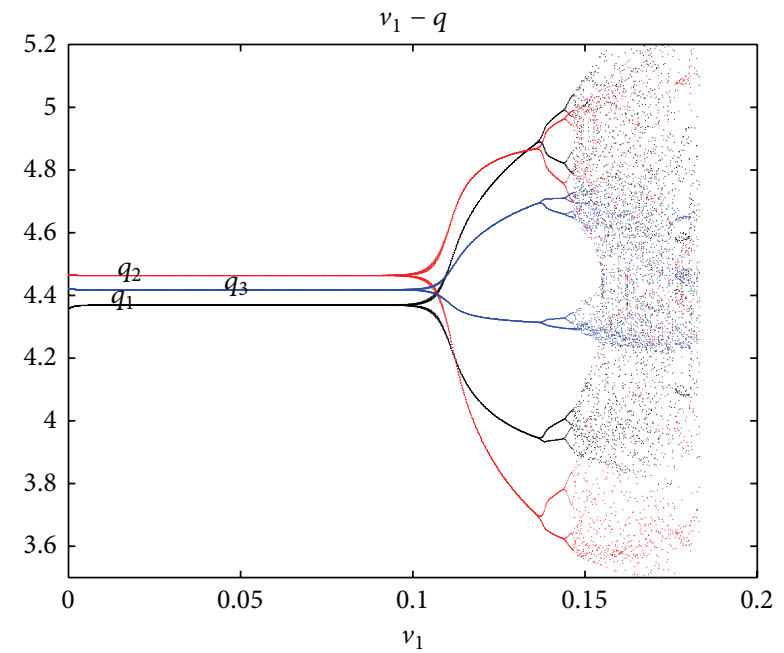

FIgURE 2: Quantity bifurcation with the change of $v_{1}$.

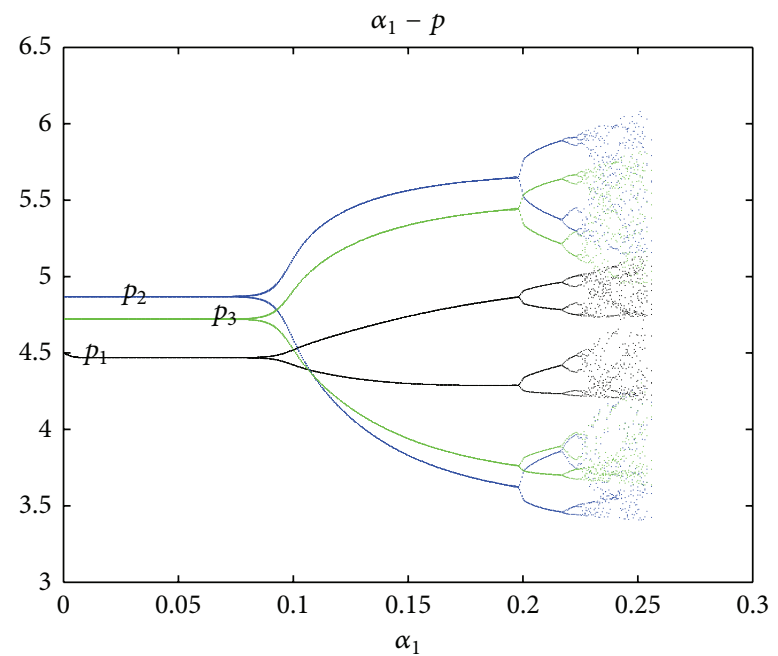

FIgURe 3: Price bifurcation with the change of $\alpha_{1}$.

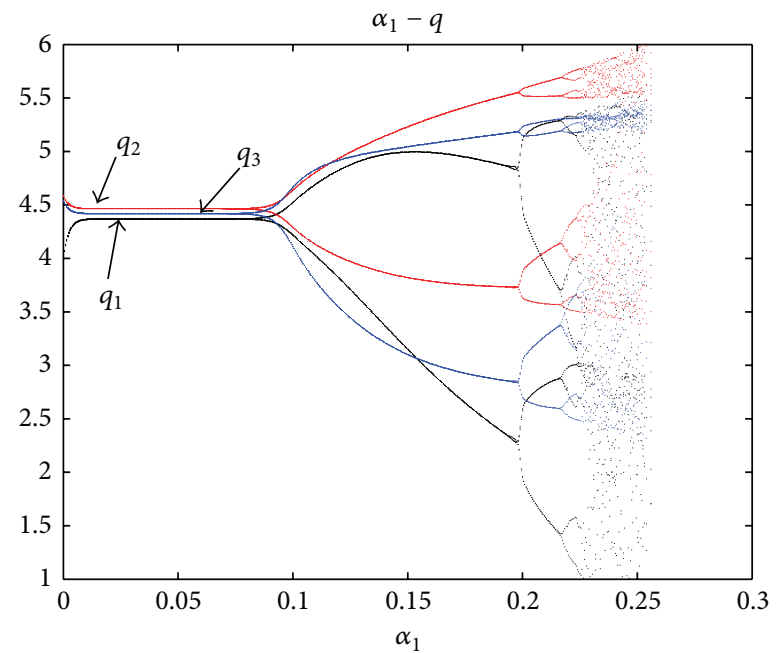

FIGURE 4: Quantity bifurcation with the change of $\alpha_{1}$.

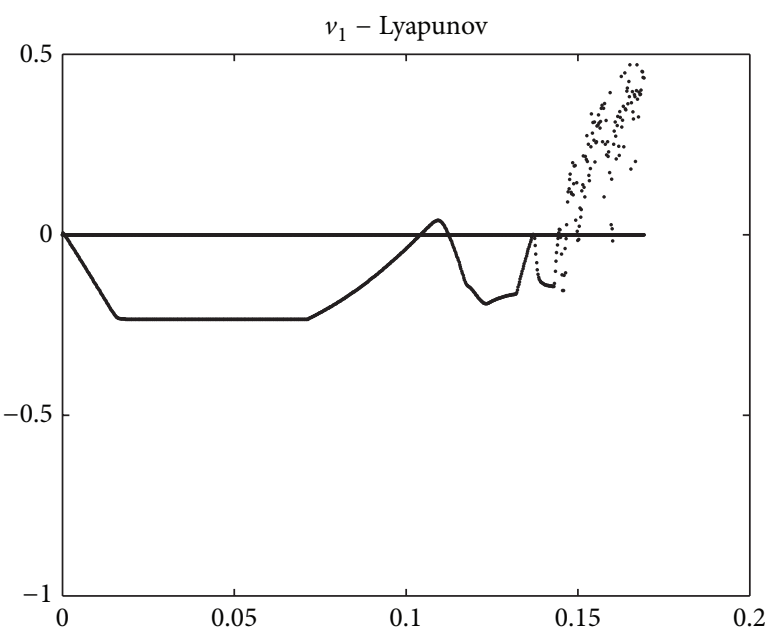

Figure 5: Lyapunov index with the change of $v_{1}$.

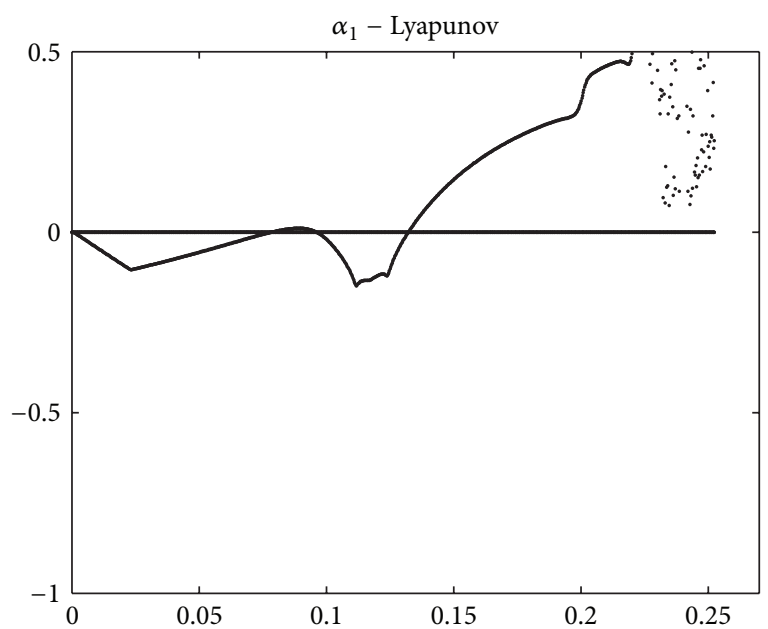

Figure 6: Lyapunov index with the change of $\alpha_{1}$.

Besides, we note that, in Figures 3 and 4, when $\alpha_{1}$ gradually increases, after the first bifurcation of $p_{i}, q_{i}$ occurred, in a wide range they remain in two-cycle state. In this situation, if we introduce chaos control to the system, the stability range will be remarkably expanded. Path entering into chaotic state is similar to the increase of $v_{1}$.

Figure 5 is the maximum Lyapunov index variation figure of $v_{1}$; observing this figure we can also confirm the bifurcation and chaos of the retailers' decision variables $p_{i}, q_{i}$, when $v_{1}$ gradually increases. Figure 6 is the maximum Lyapunov index variation figure of $\alpha_{1}$. It also shows the process of the system changing from stability to chaos, when $\alpha_{1}$ gradually increases.

Comparing Figure 5 to Figures 1 and 2, we see that when $v_{1}$ is small, $p_{i}, q_{i}$ remain stable, and the maximum Lyapunov index of the system is less than zero; with the increase of $v_{1}$, the first bifurcation of $p_{i}, q_{i}$ occurred, and it is the point where the maximum Lyapunov index of the system is zero; when $v_{1}$ kept increasing, $p_{i}, q_{i}$ came to chaos, and the maximum Lyapunov index of the system is bigger than 


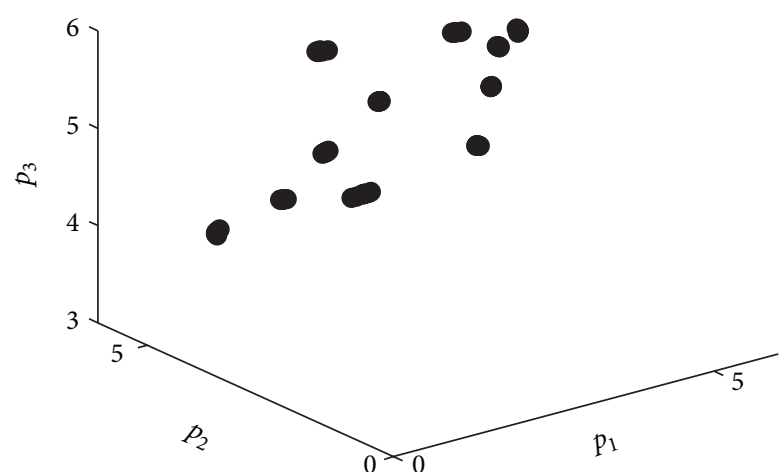

(a)

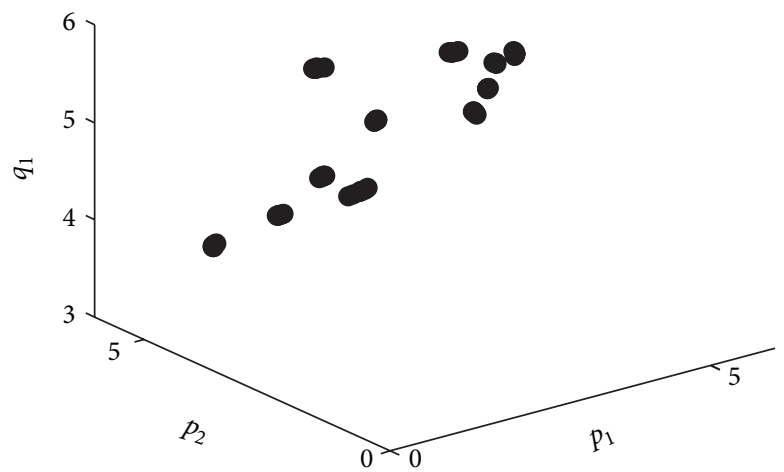

(c)

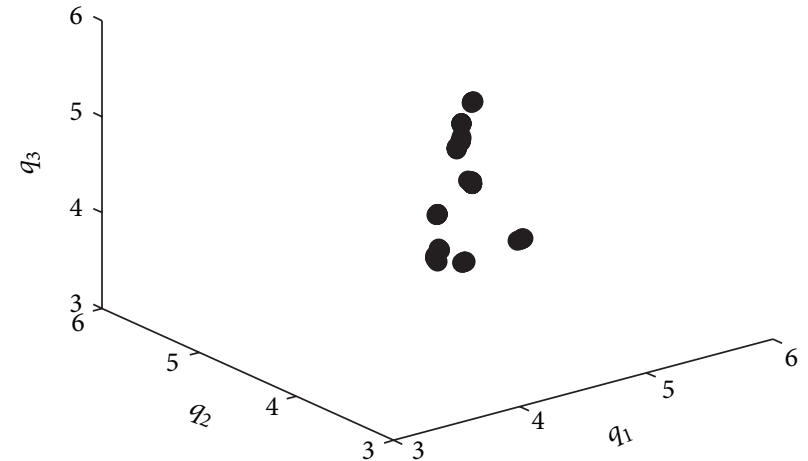

(b)

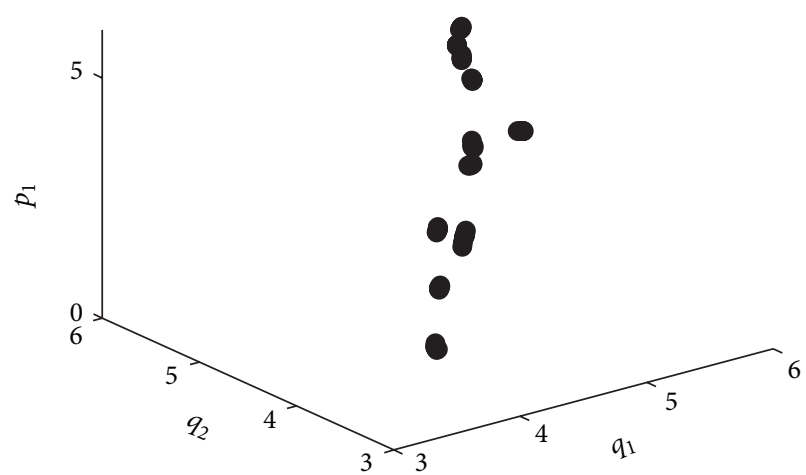

(d)

FIGURE 7: Chaos attractor of the system.

zero. The variation of the maximum Lyapunov index of $\alpha_{1}$ in Figure 6 also confirmed the process in Figures 3 and 4: $p_{i}$, $q_{i}$ change from stability to two-cycle state, then to four cycle state, and at last come to chaos.

The chaos state of the system also can be proved by its chaos attractor; when $v_{1}=0.15, v_{2}=0.05, v_{3}=0.1, \alpha_{1}=$ $0.1, \alpha_{2}=0.15$, and $\alpha_{3}=0.05$, the system is in chaos, and its chaos attractor is showed in Figure 7. From the figure, we see that the attractor of the system is divergent; it proves that the system is in chaos.

3.3. Profit Numerical Simulation. When each retailer changes its adjustment speed of its recycle price or its new product supply quantity, the decisions of them become complicated. In this situation, how would the profit of each retailer in the system become? Would it increase when the market uncertainty increases? Or would it decrease when the market became more complicated? Does every retailer's profit change in the same way? Here we still use the adjustment speed $v_{1}$, $\alpha_{1}$ of retailer 1 as an example to study. When $v_{1}$ gradually increases, Figure 8 is the track figure of each retailer's profit, and Figure 9 is the average profit track figure of the three oligarchs. When $\alpha_{1}$ gradually increases, the track of each retailer's profit is showed in Figure 10, and the average profit track of the three oligarchs is showed in Figure 11.

From Figures 8 to 11, we know that when the adjustment speed $v_{1}, \alpha_{1}$ of retailer 1 about its recycler price $p_{1}$ and new product supply quantity $q_{1}$ gradually increases, at first, each

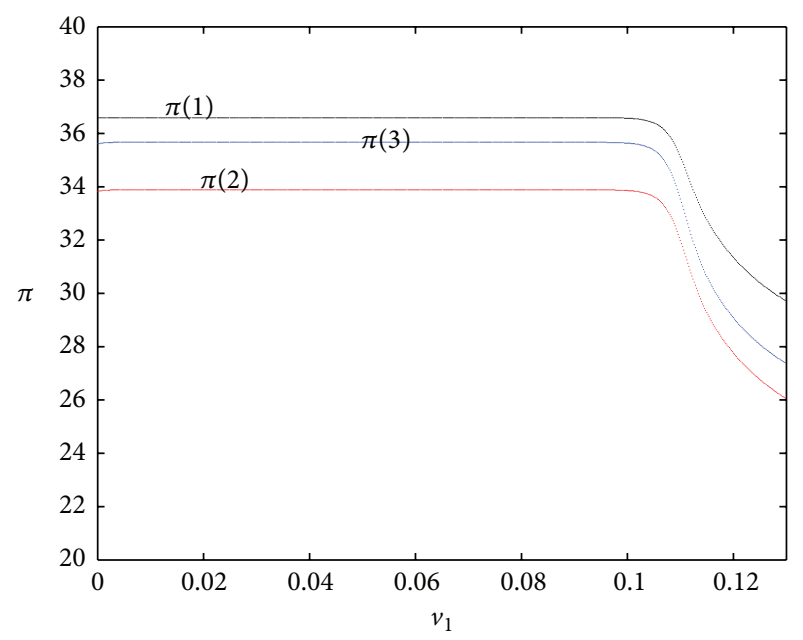

FIGURE 8: Track figure of profit with $v_{1}$.

retailer's profit and the average profit of the three oligarchs all remained stable; then when $v_{1}$ and $\alpha_{1}$ keep increasing and reach a critical value, all the profits fall fast. And the critical values of $v_{1}, \alpha_{1}$, where profits begin to fall, are the bifurcation points in Figures 1-4. Meanwhile, the maximum Lyapunov index equals zero.

So, if retailer 1 adjusts $p_{1}, q_{1}$ too fast, the system variables will become bifurcation and chaos. This means that all the decision makers' behavior in the system will be complicated, 


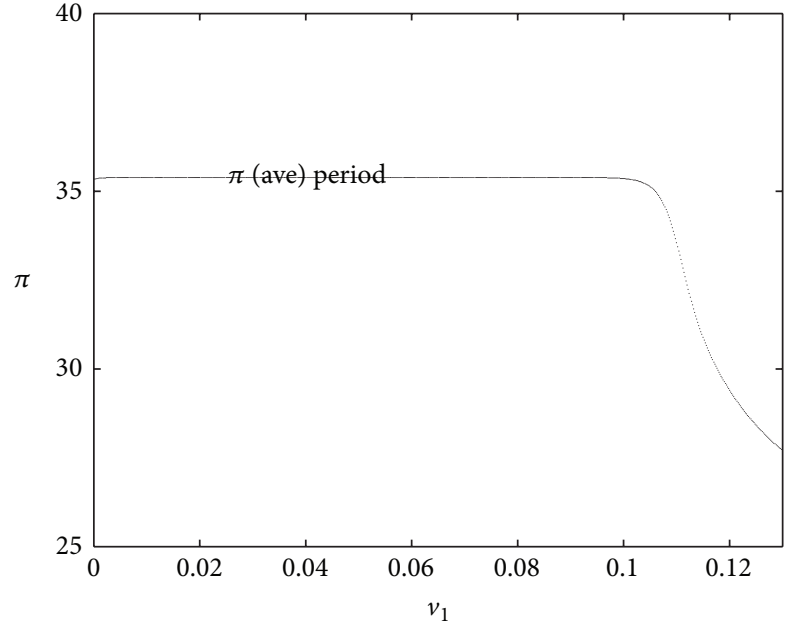

FIGURE 9: Average profit of the oligarchs with $v_{1}$.

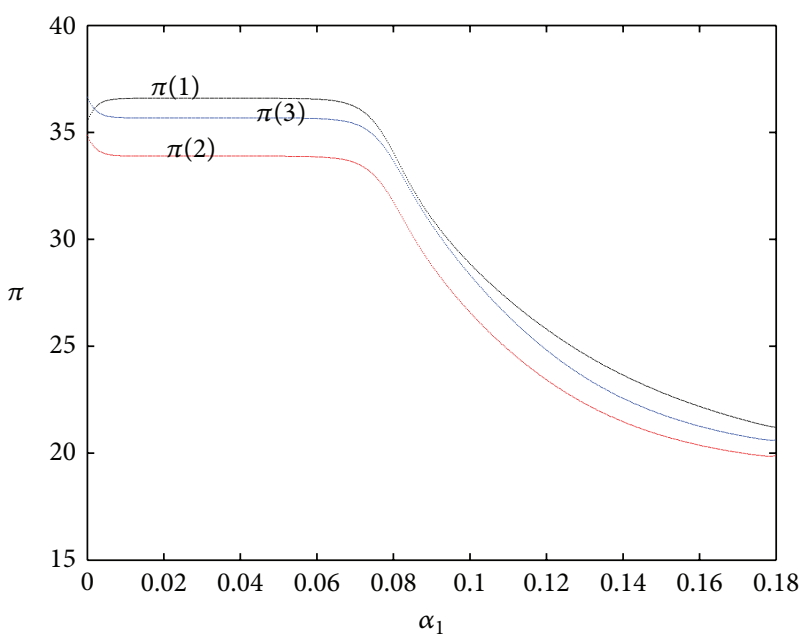

FIGURE 10: Track figure of profit with $\alpha_{1}$.

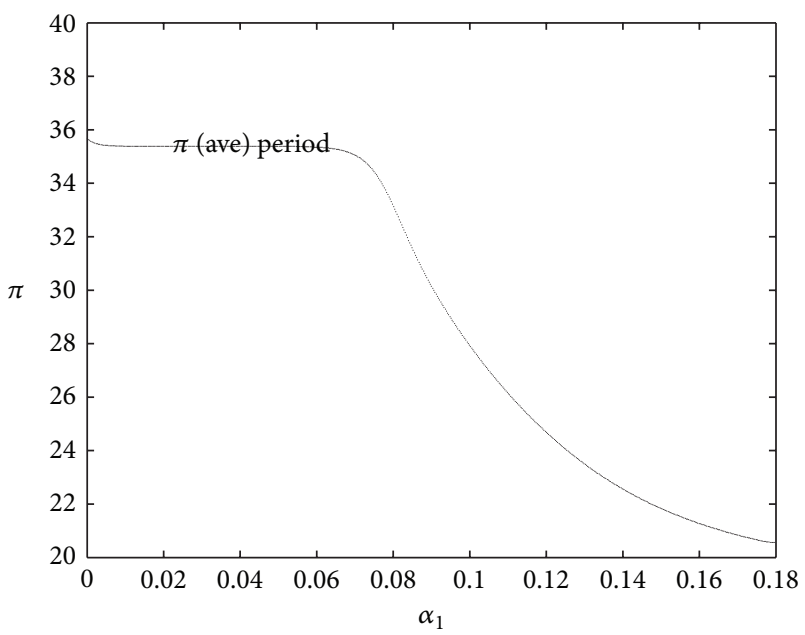

FIGURE 11: Average profit of the oligarchs with $\alpha_{1}$. and it makes the profit of each retailer and the average profit of the system all reduce. As the same, if retailer 2 or retailer 3 adjusts its decision too fast, the profits of the three oligarchs would go the same way.

Then we have the study on the power spectrum of $p_{i}, q_{i}$ when retailers adjust their recycle price $p_{i}$ and new product supply quantity $q_{i}$ in different speeds. From the result we are aware that when the system is in chaos state, the power spectrum of $p_{1}, q_{1}$ confirms that the power spectrum is continuous. Meanwhile, we know that no matter how fast retailer 1 adjusts $p_{1}, q_{1}$, the values of recycle price $p_{1}$ and new product supply quantity $q_{1}$ would go through every value in the value area, and they will always be restricted within a certain value range. These are the chaos characteristics of the system: from inside, the chaotic motions of the system are irregular; from outside, the chaotic motions have a certain value space. It is the chaos attractor. So, the chaos is bounded; this is the foundation of the system chaos control.

\section{System Chaos Control}

When the system changes from stability to chaos, all the three-oligarch retailers' decisions become complicated, and the profit of each one declines fast, so no retailer expects the chaos. In this case, the three oligarch retailers can put some adjustment measures to the market, through the coordination and cooperation between them to control the system chaos, in order to delay or eliminate the chaos in the market and assure that their profits reach the maximum.

In this paper, we will use parameter adjustment and variable state feedback control strategy, to control the three retailers' recycle price $p_{i}$ and new product supply quantity $q_{i}$, in order to delay the chaos of the system.

Note the original discrete dynamic system (6) as follows:

$$
\begin{array}{r}
p_{i}(t+1)=f_{i}\left(p_{1}(t), p_{2}(t), p_{3}(t), q_{1}(t), q_{2}(t), q_{3}(t)\right), \\
i=1,2,3, \\
q_{j}(t+1)=g_{j}\left(p_{1}(t), p_{2}(t), p_{3}(t), q_{1}(t), q_{2}(t), q_{3}(t)\right), \\
j=1,2,3 .
\end{array}
$$

Put the parameter adjustment and variable state feedback control strategy to it:

$$
\begin{aligned}
p_{i}(t+m) & \\
= & (1-\mu) f_{i}^{m}\left(p_{1}(t), p_{2}(t), p_{3}(t), q_{1}(t), q_{2}(t), q_{3}(t)\right) \\
& +\mu p_{i}(t), \quad i=1,2,3, \\
q_{j}( & +m) \\
= & (1-\mu) g_{j}^{m}\left(p_{1}(t), p_{2}(t), p_{3}(t), q_{1}(t), q_{2}(t), q_{3}(t)\right) \\
& +\mu q_{i}(t), \quad j=1,2,3 .
\end{aligned}
$$


In (12), $0<\mu<1$ is the adjustment parameter, and $m$ is the iteration times in each control; here take $m=1$. Then the controlled system is as follows:

$$
\begin{aligned}
p_{i}( & +1) \\
= & (1-\mu) f_{i}\left(p_{1}(t), p_{2}(t), p_{3}(t), q_{1}(t), q_{2}(t), q_{3}(t)\right) \\
& +\mu p_{i}(t), \quad i=1,2,3, \\
q_{j}( & +1) \\
= & (1-\mu) g_{j}\left(p_{1}(t), p_{2}(t), p_{3}(t), q_{1}(t), q_{2}(t), q_{3}(t)\right) \\
& +\mu q_{i}(t), \quad j=1,2,3 .
\end{aligned}
$$

Use the same market parameters as before, and solve the controlled system (13); then we know that the value of the only Nash equilibrium is the same as system (6). It is

$$
\begin{aligned}
E= & {\left[p_{1}^{*}, p_{2}^{*}, p_{3}^{*}, q_{1}^{*}, q_{2}^{*}, q_{3}^{*}\right] } \\
= & {[4.4641,4.9662,4.7060,} \\
& 4.2869,4.4451,4.3806] .
\end{aligned}
$$

The Jacobian matrix of the equilibrium $E$ of controlled system (13) is

$$
J(E)=\left[\begin{array}{cccccc}
1-16.7134 v_{1} \mu & -0.4446 v_{1} \mu & -0.5464 v_{1} \mu & -2.4106 v_{1} \mu & -1.3392 v_{1} \mu & -1.3392 v_{1} \mu \\
-1.2414 v_{2} \mu & 1-12.6722 v_{2} \mu & -0.4138 v_{2} \mu & -1.1795 v_{2} \mu & -1.9095 v_{2} \mu & -1.1795 v_{2} \mu \\
-1.6230 v_{3} \mu & -0.0296 v_{3} \mu & 1-14.774 v_{3} \mu & -1.2941 v_{3} \mu & -1.2941 v_{3} \mu & -2.1553 v_{3} \mu \\
-2.3149 \alpha_{1} \mu & -0.4158 \alpha_{1} \mu & -0.5166 \alpha_{1} \mu & 1-6.8591 \alpha_{1} \mu & -3.4295 \alpha_{1} \mu & -3.4295 \alpha_{1} \mu \\
-0.8335 \alpha_{2} \mu & -1.7091 \alpha_{2} \mu & -0.5467 \alpha_{2} \mu & -3.5561 \alpha_{2} \mu & 1-7.1121 \alpha_{2} \mu & -3.5561 \alpha_{2} \mu \\
-0.8433 \alpha \mu_{3} & -0.3592 \alpha_{3} \mu & -2.0063 \alpha_{3} \mu & -3.5045 \alpha_{3} \mu & -3.5045 \alpha_{3} \mu & 1-7.009 \alpha_{3} \mu
\end{array}\right] .
$$

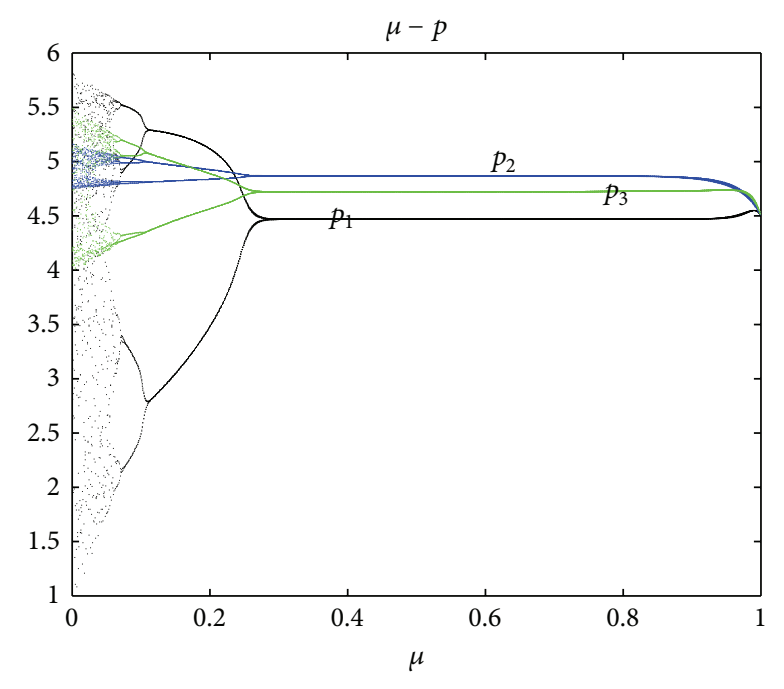

FIGURE 12: Chaos control of $p_{i}$ with parameter $\mu$.

Obviously, the value of $\mu$ has influence on the eigenvalues of the equilibrium's Jacobian matrix, so $\mu$ will affect the stable range of the Nash equilibrium.

Take $v_{1}=0.15, v_{2}=0.05, v_{3}=0.1, \alpha_{1}=0.1, \alpha_{2}=0.15$, and $\alpha_{3}=0.05$; the system is in chaos, and the influence of the adjustment parameter $\mu$ on the stability of the recycle price $p_{i}$ and new product supply quantity $q_{i}$ is showed in Figures 12 and 13.

From Figures 12 and 13 we see that when $\mu=0$, before the adjustment, the original system is in chaos; with the increase of the adjustment parameter $\mu$, the recycle price $p_{i}$ and new product supply quantity $q_{i}$ gradually change from the chaos to cycle phase; when $\mu$ reaches a critical value (about 0.3 ), the recycle price $p_{i}$ and new product supply quantity $q_{i}$ begin to keep stable, and the system chaos is well controlled.

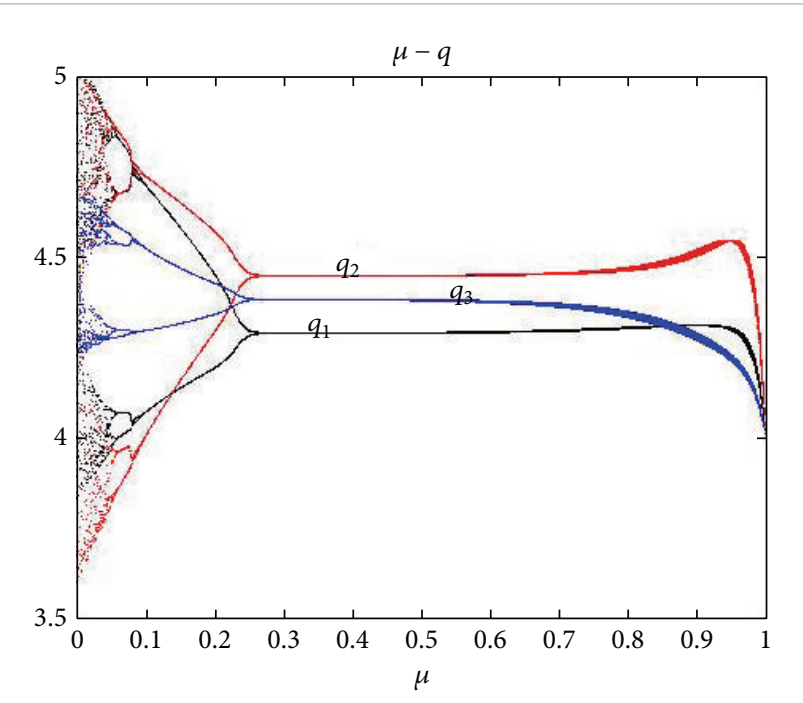

FIGURE 13: Chaos control of $q_{i}$ with parameter $\mu$.

Take $v_{2}=0.05, v_{3}=0.1, \alpha_{1}=0.1, \alpha_{2}=0.15, \alpha_{3}=$ 0.05 , and $\mu=0.4$; the track figures of the recycle price $p_{i}$ and new product supply quantity $q_{i}$ when $v_{1}$ gradually increases are Figures 14 and 15. Take $v_{1}=0.05, v_{2}=0.12, v_{3}=0.1$, $\alpha_{2}=0.1, \alpha_{3}=0.15$, and $\mu=0.4$; the track figures of the recycle price $p_{i}$ and new product supply quantity $q_{i}$ when $\alpha_{1}$ gradually increases are Figures 16 and 17.

Comparing Figures 14 and 15 with Figures 1 and 2, we noticed that the stable range of $p_{i}, q_{i}$ when $v_{1}$ increases is much larger; comparing Figures 16 and 17 with Figures 3 and 4 , we also noticed that the stable range of $p_{i}, q_{i}$ when $\alpha_{1}$ increases is much larger. This means that, through using the parameter adjustment and variable state feedback control strategy to control the chaos of the system, the stable range of the system is extremely expanded; in the condition that 


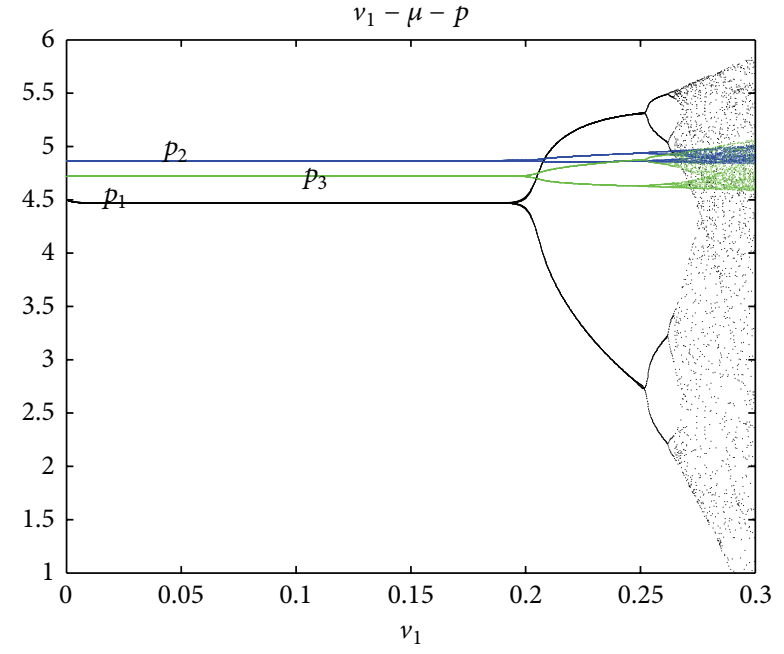

FIGURE 14: Track of $p_{i}$ with $v_{1}$ after adjustment.

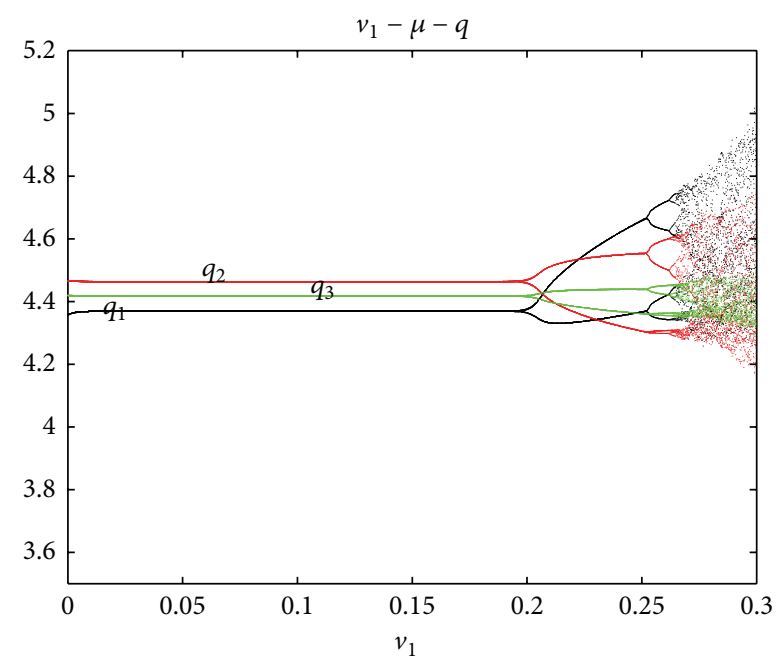

FIGURE 15: Track of the $q_{i}$ with $v_{1}$ after adjustment.

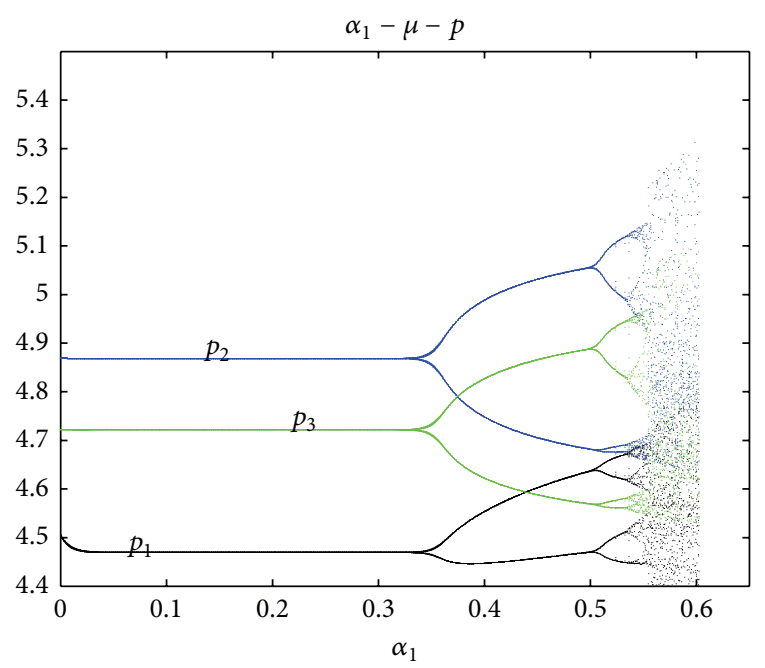

FIgURE 16: Track of $p_{i}$ with $\alpha_{1}$ after adjustment.

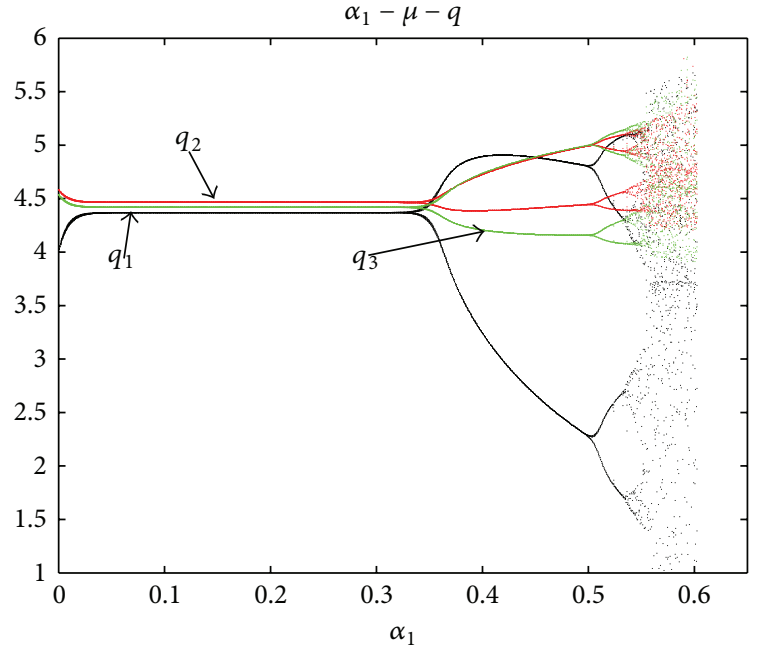

Figure 17: Track of the $q_{i}$ with $\alpha_{1}$ after adjustment.

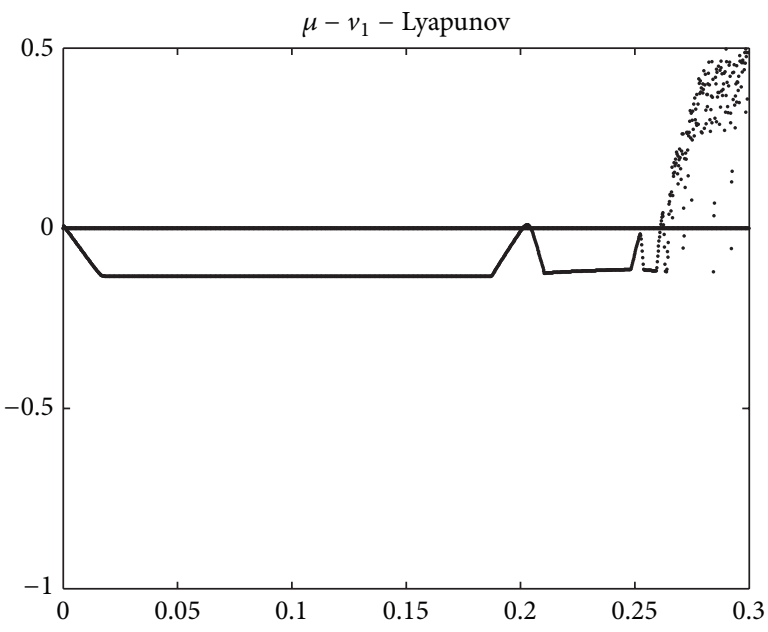

FIGURE 18: Lyapunov index variations of $v_{1}$.

the market stays stable, the retailers' adjustment range can be much larger; it gives the retailers greater flexibility when they are making their decisions.

The larger stability range and the greater flexibility also can be reflected by the maximum Lyapunov index variation figure of retailer 1's adjustment speed $v_{1}, \alpha_{1}$. In the case of system chaos control, the maximum Lyapunov index variation figures of $v_{1}, \alpha_{1}$ are Figures 18 and 19.

Comparing Figures 18 and 19 with Figures 5 and 6, it is obvious that the maximum Lyapunov index of $v_{1}, \alpha_{1}$ remains less than zero in a much larger range. When the maximum Lyapunov index of the system is less than zero, the system stays stable, so now the system has a larger stable range.

From Figure 7 in Section 3.2, when $v_{1}=0.15, v_{2}=0.05$, $v_{3}=0.1, \alpha_{1}=0.1, \alpha_{2}=0.15$, and $\alpha_{3}=0.05$, the system is in chaos, and the attractor of the system is divergent. After the system chaos control, take $\mu=0.4$; the new attractor of the system is showed in Figure 20. We see that the attractor 


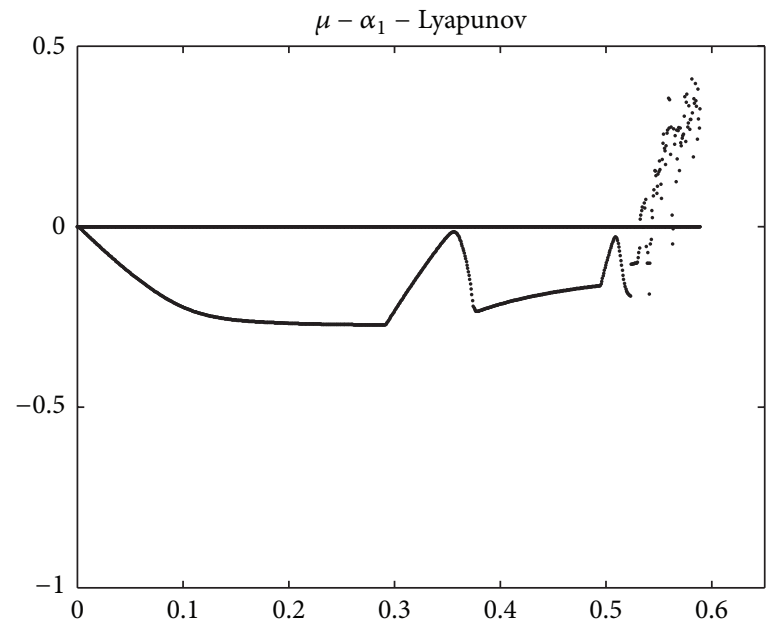

FIGURE 19: Lyapunov index variations of $\alpha_{1}$.

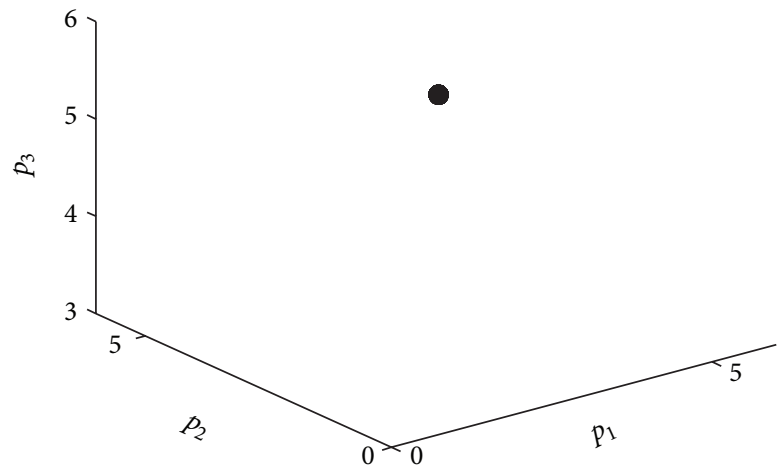

(a)

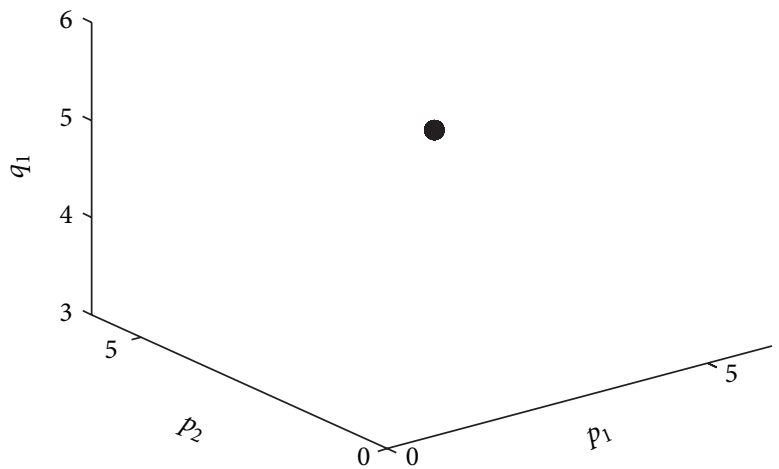

(c)

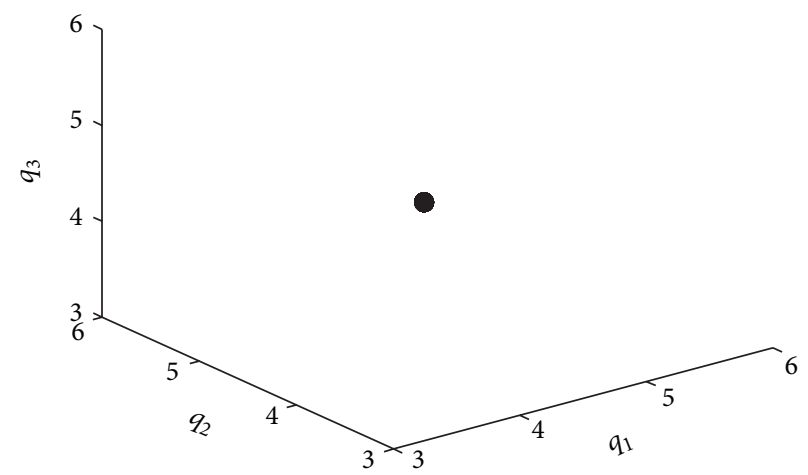

(b)

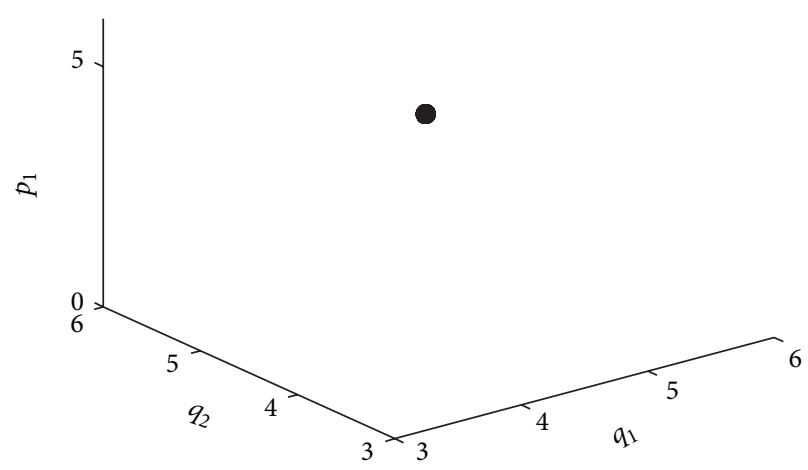

(d)

FIGURE 20: Chaos attractor of the system after adjustment.

in Figure 20 is a point; it means that the system now is stable, and the chaos of the system is controlled effectively.

According to the analyses of the three retailers' profit and their average profit in Section 3.3, when the system is stable, each of the three oligarch retailers' profit and their average profit are all stable and maximal; when the system is in chaos, each of the three oligarch retailers' profit and their average profit all fall fast. Through the system chaos control, the chaos of the system is delayed, and the stable range of the system is expanded, so the stable range of the three oligarch retailers' profit becomes much larger, and it means a lot to the improvement of the retailers' profit.

In the reality of economic life, the value of the adjustment parameter $\mu$ is determined by the three oligarch retailers together, to make sure that they all get a stable and satisfied profit. Meanwhile, the three oligarch retailers also need to 
control their adjustment speed of $p_{i}, q_{i}$, to make sure that the market remains stable and their own profit reaches the maximum.

\section{Conclusions}

In this paper, the model of a closed-loop supply chain based on price difference between new and second-hand products is established, and the game and complexity theory of the three oligarch retailers is discussed. Through numerical simulation, the conclusions are as follows.

(1) The retailers' adjustment speed about their recycle price and new product supply quantity has no influence on the value of the system equilibrium, but the adjustment speed would affect the stable range of the equilibrium.

(2) When the retailers adjust their recycle price and new product supply quantity too fast, the market behavior becomes complicated, and each retailer's decision variables go to chaos; at the same time, the three oligarch retailers' profit declines very fast.

(3) No matter what the inside of the system chaos is like, the value of the system variables would be restricted within a certain value range; the ergodicity and the boundedness are the foundation of chaos control.

(4) Chaos control can delay the system chaos state effectively and enlarge the system decision stable range.

Referencing to the model built in this paper, the participants in the supply chain can adjust their own decisions effectively in different time, and they can also work together to control the chaos in the supply chain. So the paper has a strong practical guiding significance to the market stability and the improvement of the retailers' profits. Besides, this paper studied the closed-loop supply chain with game and complexity theory and meanwhile combined the sale of the new product with the recycle and sale of the waste product, so it also has a certain reference value to the theory research of the closed-loop supply chain. The results of this paper provide the direction for further research on closed-loop supply chain with a time delay characteristics.

\section{Conflict of Interests}

The authors declare that there is no conflict of interests regarding the publication of this paper.

\section{Acknowledgments}

The authors thank the reviewers for their careful reading and providing some pertinent suggestions. The research was supported by the National Natural Science Foundation of China (no. 61273231), Doctoral Fund of Ministry of Education of China (Grant no. 20130032110073), and Tianjin University Innovation Fund.

\section{References}

[1] J. Zhang and Q. Da, "Analysis of duopoly game with different rationality in oligopoly market," Journal of Southeast University, vol. 36, no. 6, pp. 1029-1033, 2006.
[2] A. Matsumoto and Y. Nonaka, "Statistical dynamics in a chaotic Cournot model with complementary goods," Journal of Economic Behavior and Organization, vol. 61, no. 4, pp. 769-783, 2006.

[3] Y. L. Lu, H. F. Xue, and Z. G. Li, "Complex dynamics analysis and chaos control for an economic game model," System Engineering Theory and Practice, vol. 28, no. 4, pp. 118-123, 2008.

[4] E. M. Elabbasy, H. N. Agiza, and A. A. Elsadany, "Analysis of nonlinear triopoly game with heterogeneous players," Computers and Mathematics with Applications, vol. 57, no. 3, pp. 488499, 2009.

[5] Y. Gong and B. Li, "Analysis of price and differentiation strategies in tripoly market with different game structures," Systems Engineering, vol. 28, no. 4, pp. 59-63, 2010.

[6] R. Hu and Q. Chen, "Competition analysis and chaos control in duopoly of bounded rationality with learning ability," Control and Decision, vol. 26, no. 1, pp. 133-140, 2011.

[7] J. Ma and X. Pu, "Complex dynamics in nonlinear triopoly market with different expectations," Discrete Dynamics in Nature and Society, vol. 2011, Article ID 902014, 2011.

[8] J. Ma and X. Pu, “The research on Cournot-Bertrand duopoly model with heterogeneous goods and its complex characteristics," Nonlinear Dynamics, vol. 72, no. 4, pp. 895-903, 2013.

[9] J. Zhang and J. Ma, "Research on the price game model for four oligarchs with different decision rules and its chaos control," Nonlinear Dynamics, vol. 70, no. 1, pp. 323-334, 2012.

[10] J. Ma and Z. Sun, “The research on price game model and its complex characteristics of triopoly in different decision-making rule," Nonlinear Dynamics, vol. 71, no. 1-2, pp. 35-53, 2013.

[11] H. Wang and J. Ma, "Complexity analysis of a cournotbertrand duopoly game model with limited information," Discrete Dynamics in Nature and Society, vol. 2013, Article ID 287371, 6 pages, 2013.

[12] J. Ma and H. I. Bangura, "Complexity analysis research of financial and economic system under the condition of three parameters' change circumstances," Nonlinear Dynamics, vol. 70, no. 4, pp. 2313-2326, 2012.

[13] M. Junhai and Z. Junling, "Research on the price game and the application of delayed decision in oligopoly insurance market," Nonlinear Dynamics, vol. 70, no. 4, pp. 2327-2341, 2012.

[14] J. Ma and H. Tu, "Complexity of a duopoly game in the electricity market with delayed bounded rationality," Discrete Dynamics in Nature and Society, vol. 2012, Article ID 698270, 13 pages, 2012.

[15] Z. Sun and J. Ma, "Complexity of triopoly price game in Chinese cold rolled steel market," Nonlinear Dynamics, vol. 67, no. 3, pp. 2001-2008, 2012.

[16] J. Ding, Q. Mei, and H. Yao, "Dynamics and adaptive control of a Duopoly advertising model based on heterogeneous expectations," Nonlinear Dynamics, vol. 67, no. 1, pp. 129-138, 2012.

[17] Y. Yi, "Closed-loop supply chain game models with product remanufacturing in a duopoly retailer channel," Journal of Management Sciences in China, vol. 12, no. 6, pp. 45-54, 2009.

[18] Y. Guo, J. Ma, and G. Wang, "Modeling and analysis of recycling and remanufacturing systems by using repeated game model," Industrial Engineering Journal, vol. 14, no. 5, pp. 66-70, 2011.

[19] W. M. Ma and Z. Zhao, "Different models of closed-loop supply chain with the government replacement-subsidy," System Engineering Theory and Practice, vol. 32, no. 9, pp. 1938-1944, 2012. 


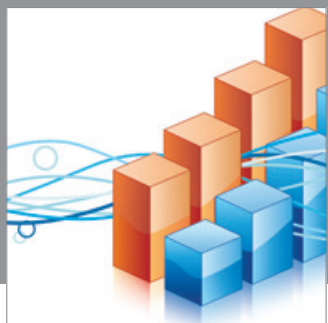

Advances in

Operations Research

mansans

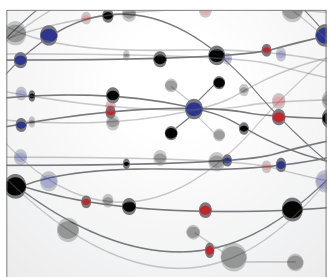

The Scientific World Journal
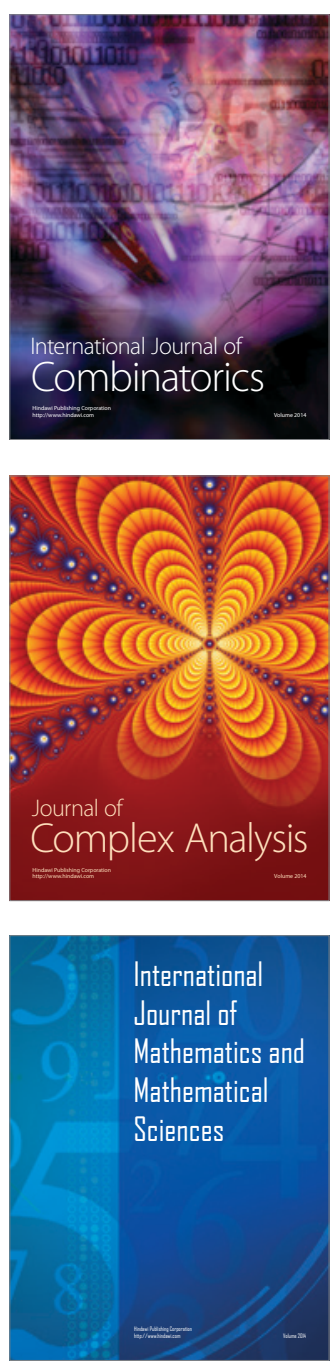
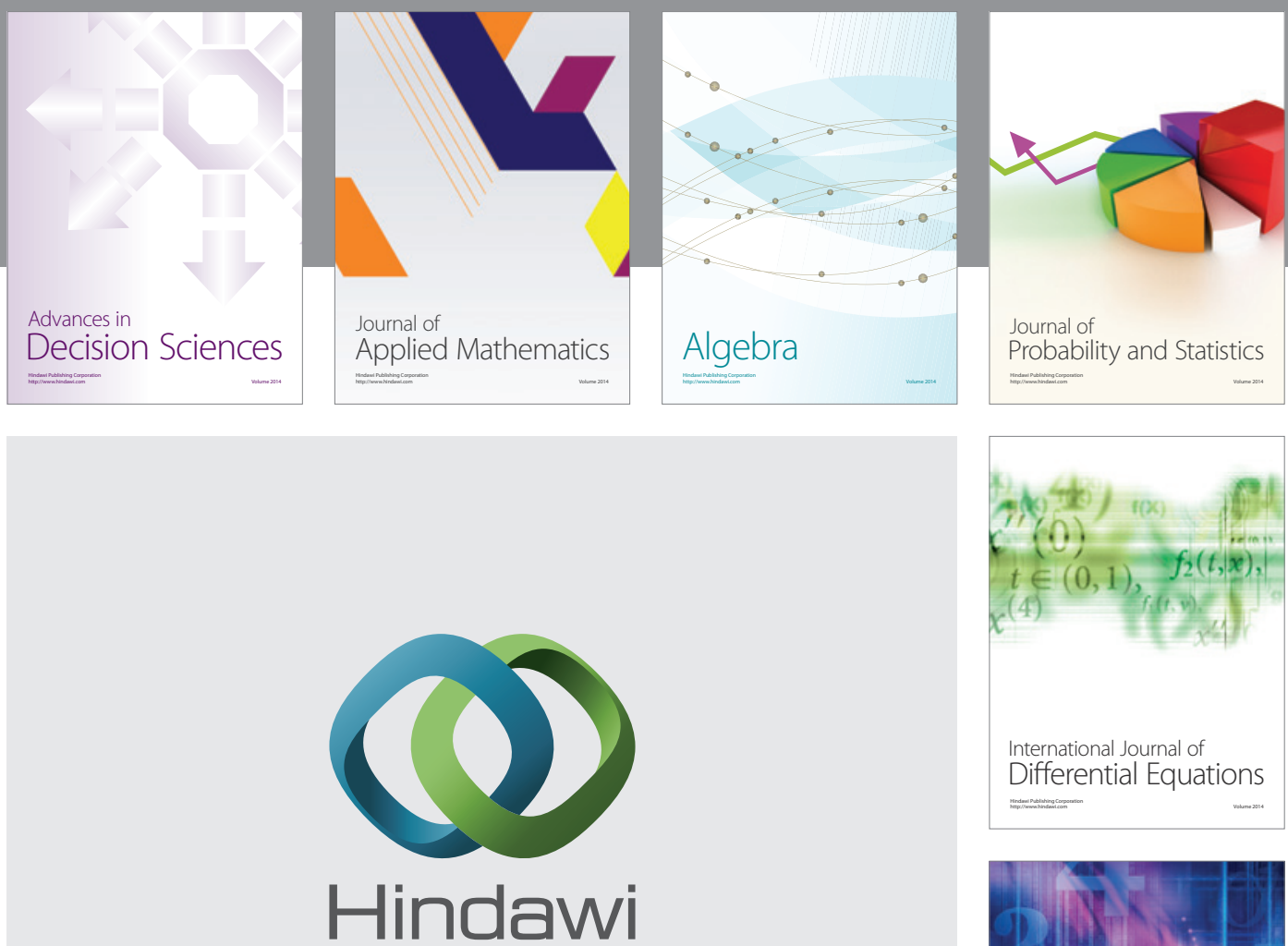

Submit your manuscripts at http://www.hindawi.com
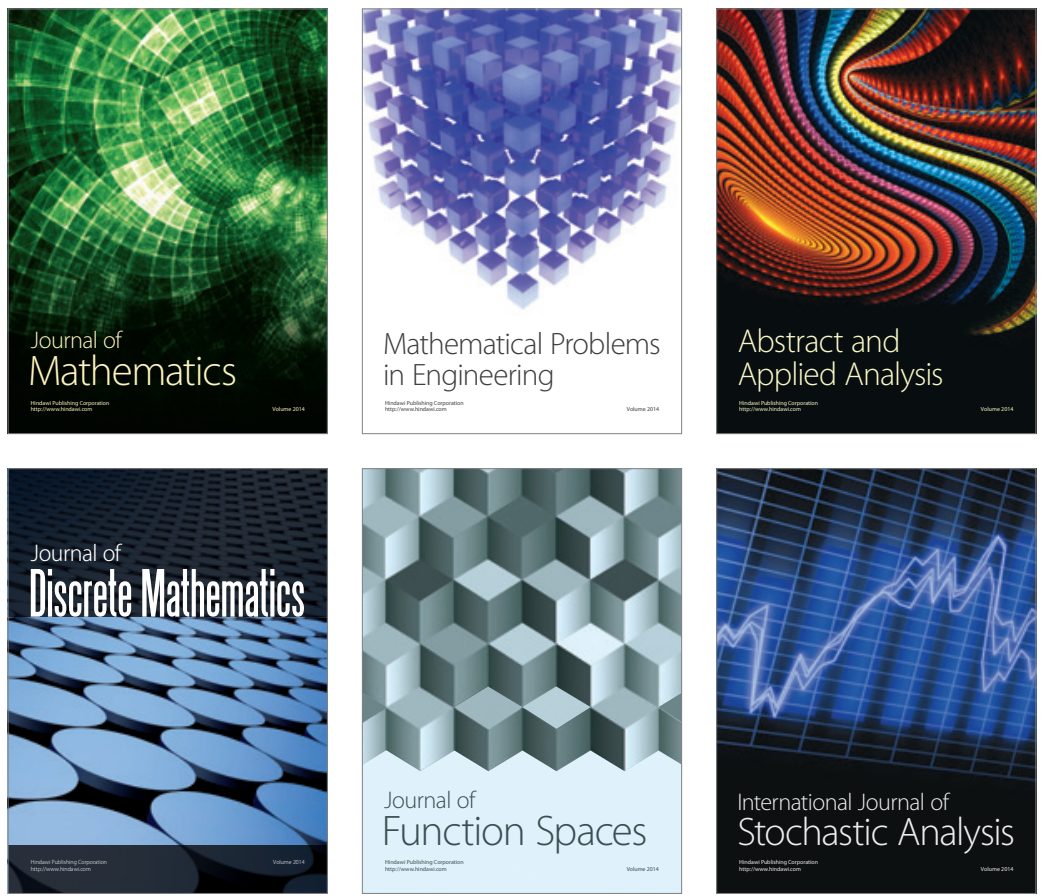

Journal of

Function Spaces

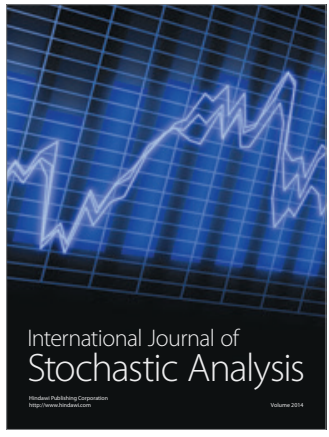

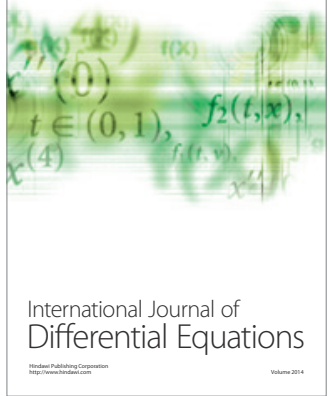
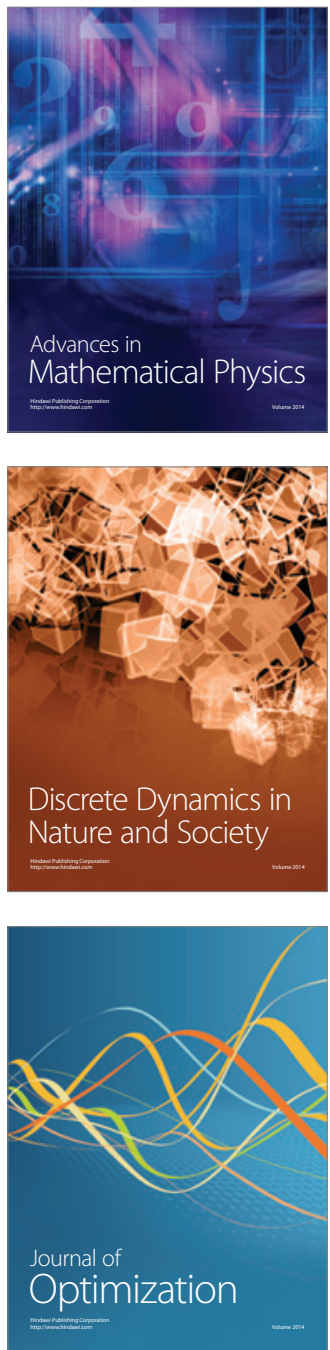